\title{
Effect of lonizing Beta Radiation on the Mechanical Properties of Poly(ethylene) under Thermal Stress
}

\author{
Martin Bednarik ${ }^{1, a}$, David Manas ${ }^{1}$, Miroslav Manas ${ }^{1}$, Ales Mizera ${ }^{1}$ and Martin Reznicek ${ }^{1}$ \\ ${ }^{1}$ Tomas Bata University in Zlin, TGM 5555, 760 01, Zlin, Czech Republic
}

\begin{abstract}
It was found in this study, that ionizing beta radiation has a positive effect on the mechanical properties of poly(ethylene). In recent years, there have been increasing requirements for quality and cost effectiveness of manufactured products in all areas of industrial production. These requirements are best met with the polymeric materials, which have many advantages in comparison to traditional materials. The main advantages of polymer materials are especially in their ease of processability, availability, and price of the raw materials. Radiation crosslinking is one of the ways to give the conventional plastics mechanical, thermal, and chemical properties of expensive and highly resistant construction polymers. Several types of ionizing radiation are used for crosslinking of polymers. Each of them has special characteristics. Electron beta and photon gamma radiation are used the most frequently. The great advantage is that the crosslinking occurs after the manufacturing process at normal temperature and pressure. The main purpose of this paper has been to determine the effect of ionizing beta radiation on the tensile modulus, strength and elongation of low and high density polyethylene (LDPE and HDPE). These properties were examined in dependence on the dosage of the ionizing beta radiation (non-irradiated samples and those irradiated by dosage $99 \mathrm{kGy}$ were compared) and on the test temperature. Radiation cross-linking of LDPE and HDPE results in increased tensile strength and modulus, and decreased of elongation. The measured results indicate that ionizing beta radiation treatment is effective tool for improvement of mechanical properties of LDPE and HDPE under thermal stress.
\end{abstract}

\section{Introduction}

Ionizing radiation is radiation at which quanta have a high energy and can knock out electrons from atomic shell and ionize the substance. Electrically neutral atoms become positive and negative ions.

The crosslinking level can be adjusted by irradiation dosage and often by means of a crosslinking booster. The main difference between electron beta and photon gamma is in their different abilities of penetrating the irradiated material. Gamma rays have a high penetration capacity. The penetration capacity of electron rays depends on the energy of the accelerated electrons. Due to accelerated electron the required dose may be applied for seconds, whereas several hours are required on the gamma radiation plant. The electron accelerators operate on the principle of the Braun tube, whereby a hot cathode is heated in vacuum to such a degree that electrons are released [1-6].

As a result of ionizing radiation, linking macromolecular chains emerge and formate the spatial grid. From the results of previous studies it is apparent, that the radiation crosslinking is very efficient method for modifying the final properties of the polymers. However, some knowledge remains unexplained so far, and therefore each new finding about the effect of radiation crosslinking on the properties of polymer materials may contribute to a better understanding of the issue and thus can extend the field of new applications [7-14].

This paper evaluates the effect of ionizing beta radiation on the mechanical properties of LDPE and HDPE under thermal stress.

\section{Experimental}

\subsection{Materials}

For this experiment LDPE (DOW LDPE 780E) and HDPE (DOW HDPE 25055E) were used. The basic properties of used materials are shown in Table 1.

The samples were made using the injection molding technology on the injection molding machine Arburg Allrounder $470 \mathrm{H} 1000-400$. The samples had the shape and dimensions according to the CSN EN ISO 527-2 (referring to: Fig. 1 and Tab. 3). Processing conditions during the injection moulding were according to the recommendation of the procedures (referring to: Tab. 2).

All samples were irradiated with electron (beta) rays (electron energy $10 \mathrm{MeV}$, radiation dose: $99 \mathrm{kGy}$ ) in the firm BGS Beta Gamma Service GmbH \& Co, Saal am Danau - Germany [6, 8, 9].

\footnotetext{
$\overline{\mathrm{a}}$ Corresponding author: mbednarik@ft.utb.cz
} 
Table 1. Properties of LDPE and HDPE.

\begin{tabular}{|c|c|}
\hline \multicolumn{2}{|c|}{ LDPE } \\
\hline Density $\left[\mathrm{g} / \mathrm{cm}^{3}\right]$ & 0.923 \\
\hline Molding shrinkage [\%] & 1.9 \\
\hline Tensile strength [MPa] & 10.5 \\
\hline Shore hardness [Shore D] & 49 \\
\hline Tensile impact strength $\left[\mathrm{kJ} / \mathrm{m}^{2}\right]$ & 286 \\
\hline \multicolumn{2}{|c|}{ HDPE } \\
\hline Density $\left[\mathrm{g} / \mathrm{cm}^{3}\right]$ & 0.955 \\
\hline Molding shrinkage [\%] & 2.1 \\
\hline Tensile strength [MPa] & 27 \\
\hline Shore hardness [Shore D] & 65 \\
\hline Tensile impact strength $\left[\mathrm{kJ} / \mathrm{m}^{2}\right]$ & 55 \\
\hline
\end{tabular}

Table 2. Injection conditions.

\begin{tabular}{|l|c|}
\hline \multicolumn{2}{|c|}{ LDPE } \\
\hline \hline Injection pressure [MPa] & 60 \\
\hline Injection rate [mm/s] & 50 \\
\hline Injection time [s] & 0.4 \\
\hline Cooling time [s] & 30 \\
\hline Mold temperature [ $\left.{ }^{\circ} \mathrm{C}\right]$ & 40 \\
\hline & \\
\hline Injection pressure [MPa] & \\
\hline Injection rate [mm $/ \mathrm{s}]$ & \\
\hline Injection time [s] & 60 \\
\hline Cooling time [s] & \\
\hline Mold temperature $\left[{ }^{\circ} \mathrm{C}\right]$ & \\
\hline
\end{tabular}

\subsection{Tensile test}

For testing the mechanical properties there was used a tensile test on the test machine Zwick 1456. Test conditions were according to the CSN EN ISO 527 - 1 and CSN EN ISO $527-2$. Speed was $50 \mathrm{~mm} / \mathrm{min}$ and test data was processed by Test Xpert Standard software and tensile strength $(\sigma \mathrm{t}[\mathrm{MPa}])$, tensile modulus (E $[\mathrm{MPa}])$ and elongation $(\varepsilon \sigma \mathrm{t}[\%])$ were determined $[6,8$, 9].
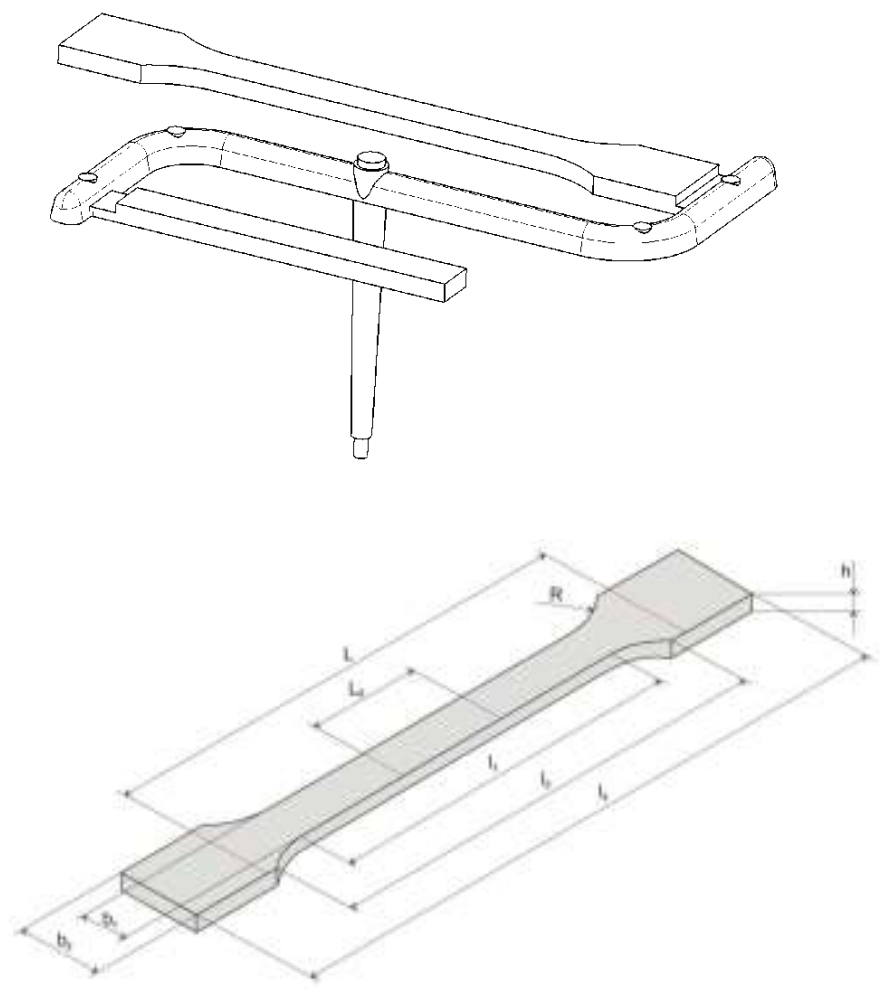

Figure 1. Testing specimens.

Table 3. Specimen dimensions.

\section{Test specimen parameters}

\begin{tabular}{lc}
\hline $\mathrm{b}_{1}$ - Width of Gage Length & $10 \pm 0.2[\mathrm{~mm}]$ \\
\hline $\mathrm{b}_{2}$ - Width of Gripping End & $20 \pm 0.2[\mathrm{~mm}]$ \\
$\mathrm{l}_{1}$ - Length of gage Length & $80 \pm 2[\mathrm{~mm}]$ \\
$\mathrm{l}_{2}$ - Distance Between Gripping Ends & $104-113[\mathrm{~mm}]$ \\
$\mathrm{l}_{3}$ - Specimen Length & $\geq 150[\mathrm{~mm}]$ \\
$\mathrm{L}_{0}$ - Distance of Extensometers & $30 \pm 0.5[\mathrm{~mm}]$ \\
\hline - Distance of Grips & $115 \pm 1[\mathrm{~mm}]$ \\
$\mathrm{h}$ - Specimen Thickness & $4 \pm 0.2[\mathrm{~mm}]$ \\
\hline $\mathrm{R}$ - Radius & $20-25[\mathrm{~mm}]$ \\
\hline
\end{tabular}




\section{Result and discussion}

\subsection{Mechanical properties - LDPE}

Comparison of tensile strength, tensile modulus and elongation (at $23,30,40,50,60,70$, and $80^{\circ} \mathrm{C}$ ) of LDPE before and after irradiation is given in the Fig. 1, Fig. 2 and Fig. 3. The measured results clearly show, that irradiation increases tensile strength and tensile modulus of LDPE for all tested temperatures.

The highest increase in tensile strength was achieved at temperature $50{ }^{\circ} \mathrm{C}$ and the lowest change of tensile strength was measured at temperature $80^{\circ} \mathrm{C}$. In the case of temperature $50{ }^{\circ} \mathrm{C}$ the tensile strength increased from 6.8 $\mathrm{MPa}$ (non-irradiated samples) to $7.9 \mathrm{MPa}$ (dose of 99 $\mathrm{kGy}$ ), which is a hike of approximately $16 \%$ (referring to: Fig. 2).

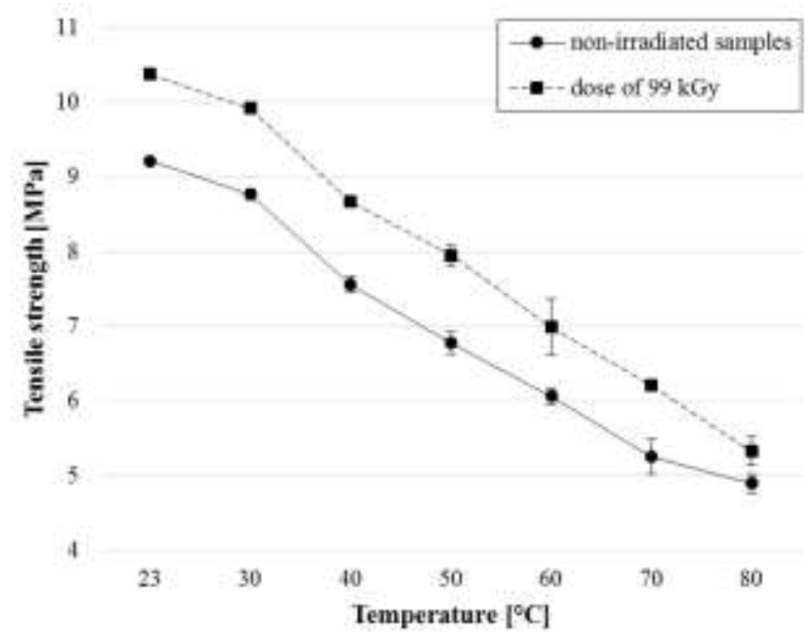

Figure 2. LDPE - variation of tensile strength $\left(\sigma_{t}\right)$.

The highest increase in tensile modulus was achieved at temperature $30{ }^{\circ} \mathrm{C}$ and the lowest change of tensile modulus was measured at temperature $80{ }^{\circ} \mathrm{C}$.

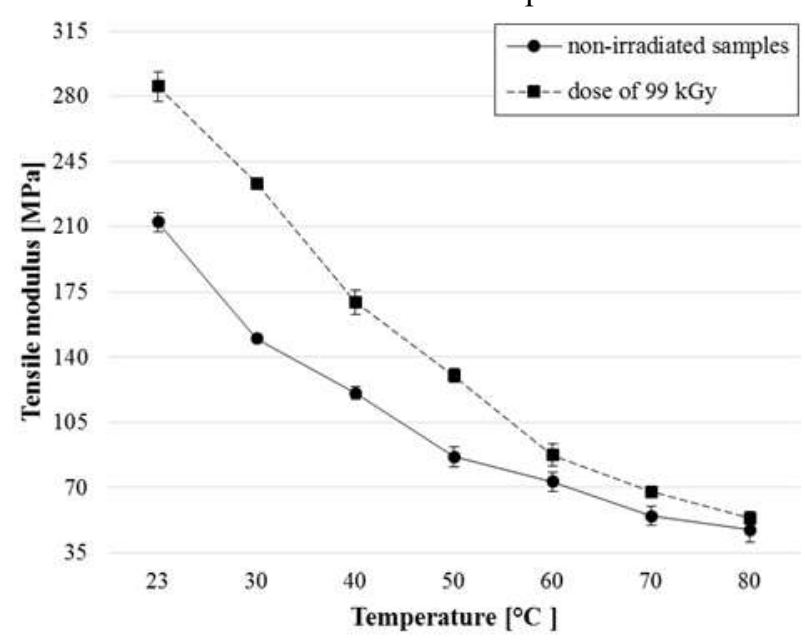

Figure 3. LDPE - variation of tensile modulus (E).

In the case of temperature $30{ }^{\circ} \mathrm{C}$ the tensile modulus increased from 149.9 $\mathrm{MPa}$ (non-irradiated samples) to
233.3 MPa (dose of $99 \mathrm{kGy}$ ), which is a hike of approximately $56 \%$ (referring to: Fig. 3 ).

The highest decrease in elongation was achieved at temperature $40{ }^{\circ} \mathrm{C}$ and the lowest change of elongation was measured at temperature $60{ }^{\circ} \mathrm{C}$. In the case of temperature $40{ }^{\circ} \mathrm{C}$ the elongation decreased from $78.3 \%$ (non-irradiated samples) to $61.6 \%$ (dose of $99 \mathrm{kGy}$ ), which is a drop of approximately $17 \%$ (referring to: Fig. 4).

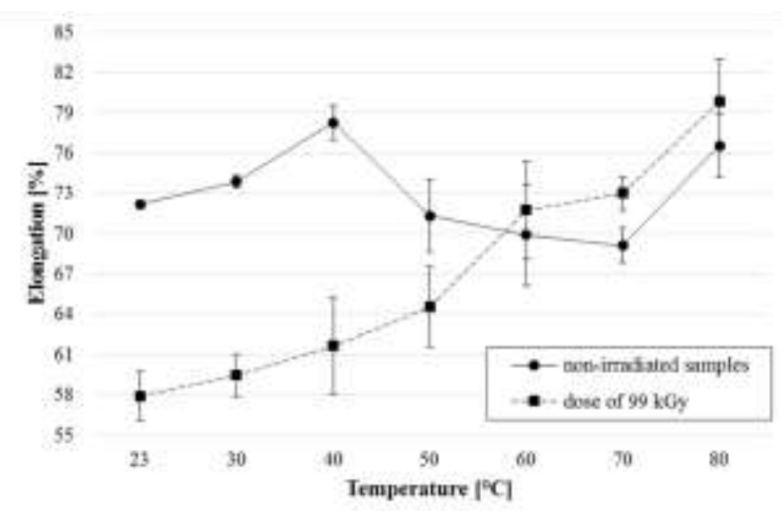

Figure 4. LDPE - variation of elongation $\left(\varepsilon_{\sigma_{t}}\right)$.

\subsection{Mechanical properties - HDPE}

Comparison of tensile strength, tensile modulus and elongation (at 23, 30, 40, 50, 60, 70, and $80^{\circ} \mathrm{C}$ ) of HDPE before and after irradiation is given in the Fig. 5, Fig. 6 and Fig. 7. The measured results clearly show, that irradiation increases tensile strength and tensile modulus of HDPE for all tested temperatures.

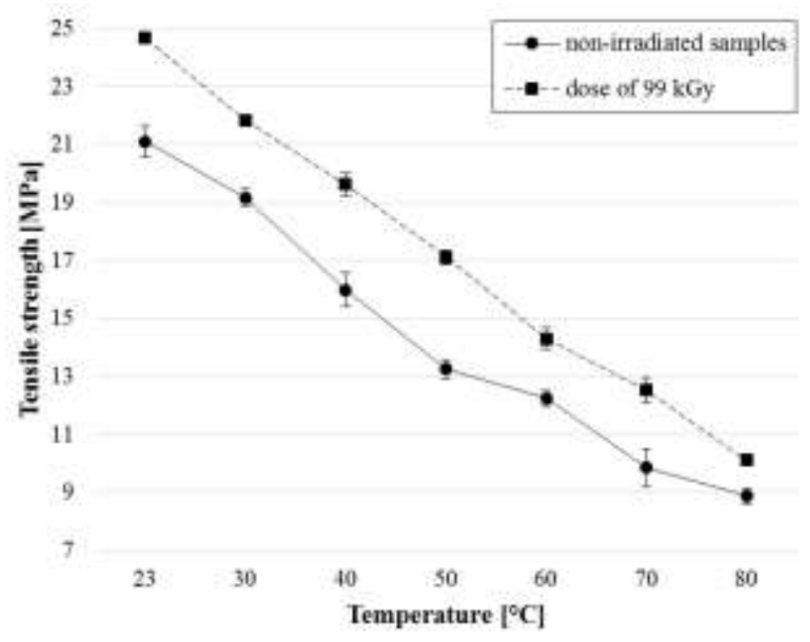

Figure 5. HDPE - variation of tensile strength $\left(\sigma_{t}\right)$.

The highest increase in tensile strength was achieved at temperature $50{ }^{\circ} \mathrm{C}$ and the lowest change of tensile strength was measured at temperature $80{ }^{\circ} \mathrm{C}$. In the case of temperature $50{ }^{\circ} \mathrm{C}$ the tensile strength increased from 13.3 $\mathrm{MPa}$ (non-irradiated samples) to $17.1 \mathrm{MPa}$ (dose of $99 \mathrm{kGy}$ ), which is a hike of approximately $29 \%$ (referring to: Fig. 5).

The highest increase in tensile modulus was achieved at room temperature $\left(23^{\circ} \mathrm{C}\right)$ and the lowest change of 
tensile modulus was measured at temperature $80{ }^{\circ} \mathrm{C}$. In the case of temperature $23{ }^{\circ} \mathrm{C}$ the tensile modulus increased from 1065.4 $\mathrm{MPa}$ (non-irradiated samples) to 1299.9 $\mathrm{MPa}$ (dose of $99 \mathrm{kGy}$ ), which is a hike of approximately $22 \%$ (referring to: Fig. 6).

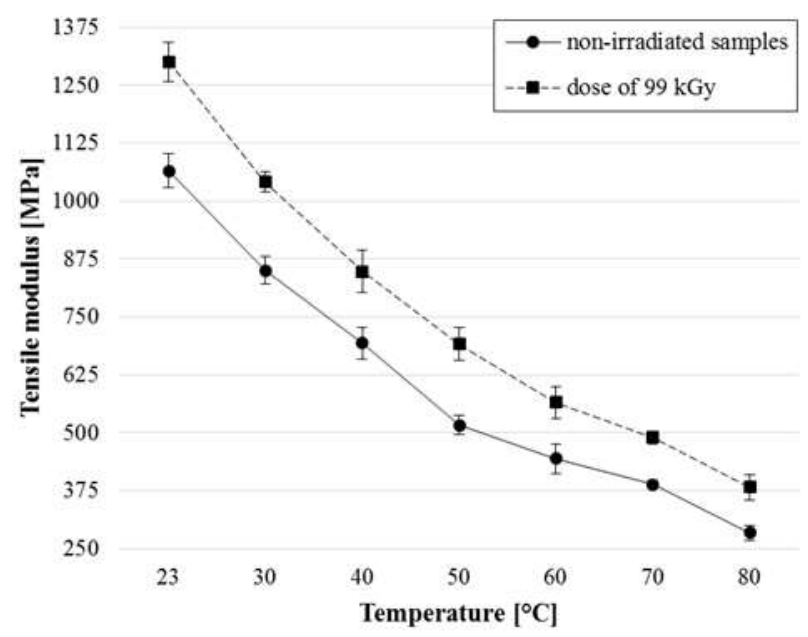

Figure 6. HDPE - variation of tensile modulus (E).

The highest decrease in elongation was achieved at temperature $80{ }^{\circ} \mathrm{C}$ and the lowest change of elongation was measured at temperature $30{ }^{\circ} \mathrm{C}$. In the case of temperature $80{ }^{\circ} \mathrm{C}$ the elongation decreased from $22.4 \%$ (non-irradiated samples) to $16.1 \%$ (dose of $99 \mathrm{kGy}$ ), which is a drop of approximately $6 \%$ (referring to: Fig. 7).

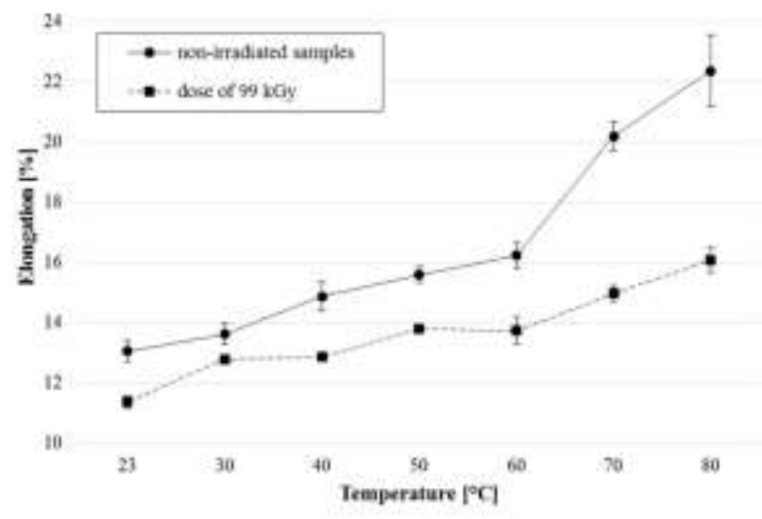

Figure 7. HDPE - variation of elongation $\left(\varepsilon_{\sigma_{t}}\right)$.

\section{Conclusion}

This article describes the effect of radiation crosslinking on the mechanical properties (tensile strength, tensile modulus and elongation) of LDPE and HDPE under thermal stress. From the measurement results follows, that the radiation crosslinking appears to be a very effective way to increase the tensile strength and tensile modulus, and decrease elongation. In the case of tensile strength was achieved of the highest increase (for LDPE and HDPE) at temperature $50^{\circ} \mathrm{C}$ (a hike of approximately
$16 \%$ - LDPE and $29 \%$ - HDPE) (referring to: Fig. 2 and Fig. 5). In the case of tensile modulus was achieved of the highest increase at temperature $30{ }^{\circ} \mathrm{C}$ (LDPE) and 23 ${ }^{\circ} \mathrm{C}$ (HDPE) (a hike of approximately $56 \%$ - LDPE and 22 $\%$ - HDPE) (referring to: Fig. 3 and Fig. 6).

In the case of elongation was achieved of the highest decrease at $40{ }^{\circ} \mathrm{C}$ (LDPE) and $80{ }^{\circ} \mathrm{C}$ (HDPE) (a drop of approximately $17 \%$ - LDPE and $6 \%$ - HDPE) (referring to: Fig. 4 and Fig. 7).

The consequence of irradiation is the creation of the covalent bonds among the macromolecular strings which are more flexible during thermal load than intermolecular forces $[6,8]$.

\section{Acknowledgments}

This paper is supported by the internal grant of TBU in Zlin No.IGA/FT/2016/010 funded from the resources of specific university research and by the Ministry of Education, Youth and Sports of the Czech Republic within the National Sustainability Programme project No. LO1303 (MSMT-7778/2014) and also by the European Regional Development Fund under the project CEBIATech No. CZ.1.05/2.1.00/03.0089.

\section{References}

1. J.G. Drobny, Radiation Technology for Polymers, CRC Press, Boca Raton (2003)

2. D. Manas, M. Manas, M. Stanek, T. Drga, Chem. Listy 101, 2 (2007)

3. D. Manas, M. Ovsik, M. Manas, M. Stanek, J. Javorik, P. Kratky, Key Eng. Materials 586, 4 (2014)

4. M. Manas, M. Stanek, D. Manas, M. Danek, Z. Holik, Chem. Listy 103, 5 (2009)

5. M. Ovsik, P. Kratky, D. Manas, M. Manas, M. Stanek, M. Bednarik, Key Eng. Materials 606, 4 (2014)

6. Z. Holik, M. Manas, M. Danek, J. Macourek, Chem. Listy 103, 4 (2009)

7. Makuuchi, S. Cheng, Radiation Processing of Polymer Materials and its Industrial Applications, Wiley, Hoboken (2011)

8. Z. Holik, M. Danek, M. Manas, R. Lamborova, J. Cerny, K. Kyas, M. Krumal, M. Malachova, Chem. Listy 105, 3 (2011)

9. M. Bednarik, D. Manas, M. Ovsik, M. Manas, M. Stanek, S. Sanda, P. Kratky, Key Eng. Materials 586, 4 (2014)

10. D.W. Clegg, A.A. Collyer, Elsevier Science Publications (1991)

11. R.L. Clough, S.W. Shalaby, American Chem. Soc. (1996)

12. S.M. Tamboli, S.T. Mhaske, D.D. Kale, Indian J. Chem. Tech. 11, 12 (2004)

13. H.A. Khonakdar, S.H. Jafari, U. Wagenknecht, D. Jehnichen, Radiat. Phys. Chem. 75, 9 (2006)

14. S.P. Hlangothi, I. Krupa, V. Djoković, A.S. Luyt, Polym. Degrad. Stabil. 79, 7 (2003) 